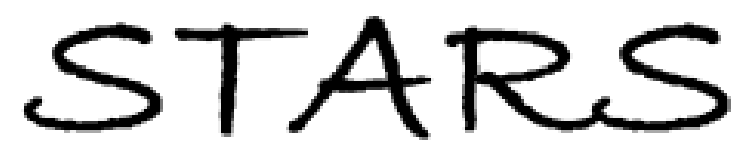

University of Central Florida

STARS

Faculty Bibliography 2000s

Faculty Bibliography

$1-1-2005$

\title{
Raman gain measurements of thallium-tellurium oxide glasses
}

\author{
Robert Stegeman \\ University of Central Florida \\ Clara Rivero \\ University of Central Florida \\ Kathleen Richardson \\ University of Central Florida \\ George Stegeman \\ University of Central Florida \\ Peter Delfyett Jr. \\ University of Central Florida
}

Find similar works at: https://stars.library.ucf.edu/facultybib2000

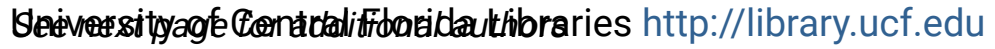

This Article is brought to you for free and open access by the Faculty Bibliography at STARS. It has been accepted for inclusion in Faculty Bibliography 2000s by an authorized administrator of STARS. For more information, please contact STARS@ucf.edu.

\section{Recommended Citation}

Stegeman, Robert; Rivero, Clara; Richardson, Kathleen; Stegeman, George; Delfyett, Peter Jr.; Guo, Yu; Pope, April; Schulte, Alfons; Cardinal, Thierry; Thomas, Philippe; and Champarnaud-Mesjard, Jean-Claude, "Raman gain measurements of thallium-tellurium oxide glasses" (2005). Faculty Bibliography 2000s. 5697.

https://stars.library.ucf.edu/facultybib2000/5697

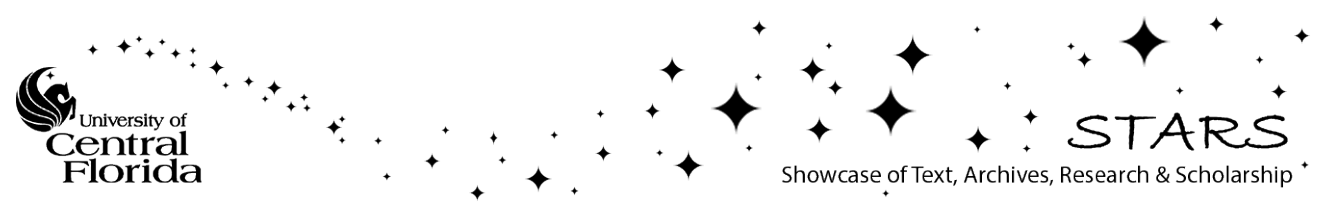




\section{Authors}

Robert Stegeman, Clara Rivero, Kathleen Richardson, George Stegeman, Peter Delfyett Jr., Yu Guo, April

Pope, Alfons Schulte, Thierry Cardinal, Philippe Thomas, and Jean-Claude Champarnaud-Mesjard 


\title{
Raman gain measurements of thallium-tellurium oxide glasses
}

\author{
Robert Stegeman, Clara Rivero, Kathleen Richardson, George Stegeman, and Peter \\ Delfyett Jr. \\ College of Optics and Photonics, University of Central Florida \\ Orlando, FL 32816-2700 \\ steg@creol.ucf.edu \\ Yu Guo, April Pope, and Alfons Schulte \\ Department of Physics, University of Central Florida \\ Orlando, FL 32816-1390 \\ Thierry Cardinal \\ Institut de Chimie de la Matiere Condensee de Bordeaux \\ 87 Avenue du Dr. Albert Schweitzer, 33608 Pessac cedex, France
}

\begin{abstract}
Philippe Thomas and Jean-Claude Champarnaud-Mesjard
Science des Procedes Ceramiques et Traitements de Surfaces, Faculte des Sciences et Techniques

123 Avenue Albert Thomas, 87060 Limoges cedex, France
\end{abstract}

\begin{abstract}
Several different compositions of tellurium-thallium oxide glasses were fabricated and tested for their Raman gain performance. The addition of $\mathrm{PbO}$ to the glass matrix increased the surface optical damage threshold by $60-230 \%$. The maximum material Raman gain coefficient experimentally obtained was $(58 \pm 3)$ times higher than the peak Raman gain of a $3.18 \mathrm{~mm}$ thick Corning $7980-2 \mathrm{~F}$ fused silica sample $(\Delta v=13.2 \mathrm{THz})$. The highest peak in the Raman gain spectrum of the tellurium-thallium glass is attributed to the presence of $\mathrm{TeO}_{3}$ and $\mathrm{TeO}_{3+1}$ structural units with thallium ions in the vicinity at a frequency shift near $21.3 \mathrm{THz}$.
\end{abstract}

(C) 2005 Optical Society of America

OCIS codes: (160.4330) Nonlinear optical materials; (060.2320) Fiber optics amplifiers and oscillators; (190.5650) Raman effect; (190.5890) Scattering, stimulated

\section{References and links}

1. M.N. Islam, "Raman Amplifiers for Telecommunications," IEEE J. Sel. Top. Quantum Electron. 8, 548559 (2002).

2. P. B. Hansen, G. Jacobovitz-Veselka, L. Grüner-Nielsen, A. J. Stentz, "Raman amplification or loss compensation in dispersion compensating fibre modules," Electron. Lett. 34, 1136-1137 (1998).

3. F.L Galeener, J. C. Mikkelsen Jr., R. H. Geils, W. J. Mosby, "The relative Raman cross sections of vitreous $\mathrm{SiO}_{2}, \mathrm{GeO}_{2}, \mathrm{~B}_{2} \mathrm{O}_{3}$, and $\mathrm{P}_{2} \mathrm{O}_{5}$," Appl. Phys. Lett. 32, 34-36 (1978).

4. M. E. Lines, "Raman gain estimates for high-gain optical fibers," J. Appl. Phys. 62, 4363-4370 (1987)

5. A. E. Miller, K. Nassau, K. B. Lyons, M. E. Lines, "The intensity of Raman scattering in glasses containing heavy metal oxides," J. Non-Cryst. Solids 99, 289-307 (1988).

6. M. E. Lines, "Oxide glasses for fast photonic switching: A comparative study," J. Appl. Phys. 69, 68766884 (1991).

7. K. A. Richardson, T. M. McKinley, B. Lawrence, S. Joshi, A. Villeneuve, "Comparison of nonlinear optical properties of sulfide glasses in bulk and thin film form," Opt. Mater. 10, 155-159 (1998).

8. J. M. Harbold, F. Ö. Ilday, F. W. Wise, J. S. Sanghera, V. Q. Nguyen, L. B. Shaw, I. D. Aggarwal, "Highly nonlinear As-S-Se glasses for all-optical switching," Opt. Lett. 27, 119-121 (2002). 
9. P. A. Thielen, L. B. Shaw, P. C. Pureza, V. Q. Nguyen, J. S. Sanghera, I. D. Aggarwal, "Small-core As-Se fiber for Raman amplification," Opt. Lett. 28, 1406-1408 (2003).

10. R. Slusher, G. Lenz, J. Hodelin, J. Sanghera, L. Brandon Shaw, I. D. Aggarwal, "Large Raman gain and nonlinear phase shifts in high-purity $\mathrm{As}_{2} \mathrm{Se}_{3}$ chalcogenide fibers," J. Opt. Soc. Am. B 21, 1146-1155 (2004).

11. T. Sekiya, N. Mochida, A. Ohtsuka, M. Tonokawa, "Raman spectra of $\mathrm{MO}_{1 / 2}-\mathrm{TeO}_{2}(\mathrm{M}=\mathrm{Li}, \mathrm{Na}, \mathrm{K}, \mathrm{Rb}, \mathrm{Cs}$, and Tl) glasses," J. Non-Cryst. Solids 144, 128-144 (1992).

12. B. Jeansannetas, S. Blanchandin, P. Thomas, P. Marchet, J. C. Champarnaud-Mesjard, T. Merle-Mejean, B. Frit, V. Nazabal, E. Fargin, G. Le Flem, M. O. Martin, B. Bosquet, L. Canioni, S. Le Boiteux, P. Segonds, L. Sarger, "Glass structure and optical nonlinearities in thallium(I) tellurium (IV) oxide glasses," J. Sol. St. Chem. 146, 329-335 (1999).

13. J. S. Wang, E. M. Vogel, F. Snitzer, "Tellurite glass: a new candidate for fiber devices," Opt. Mat. 3, 187203 (1994).

14. A. Mori, H. Masuda, K. Shikano, K. Oikawa, K. Kato, M. Shimizu, "Ultra-wideband tellurite-based Raman fiber amplifier," Electron. Lett. 37, 1142-1143 (2001).

15. V. V. Ravi Kanth Kumar, A. K. George, J. C. Knight, P. St. J. Russell, "Tellurite photonic crystal fiber," Opt. Express 11, 2641-2645 (2003).

16. G. Dai, F. Tassone, A. L. Bassi, V. Russo, C. E. Bottani, F. D' Amore, " $\mathrm{TeO}_{2}$-based glasses containing $\mathrm{Nb}_{2} \mathrm{O}_{5}, \mathrm{TiO}_{2}$, and $\mathrm{WO}_{3}$ for discrete Raman fiber amplification," Photon. Technol. Lett. 16, 1011-1013 (2004).

17. V. G. Plotnichenko, V. V. Koltashev, V. O. Sokolov, E. M. Dianov, I. A. Grishin, M. F. Churbanov, "Raman band intensities of tellurite glasses," manuscript in preparation.

18. R. Stegeman, L. Jankovic, H. Kim, C. Rivero, G. Stegeman, K. Richardson, P. Delfyett, Y. Guo, A. Schulte, T. Cardinal, "Tellurite glasses with peak absolute Raman gain coefficients up to 30 times that of fused silica," Opt. Lett. 28, 1126-1128 (2003).

19. C. Rivero, K. Richardson, R. Stegeman, G. Stegeman, T. Cardinal, E. Fargin, M. Couzi, V. Rodriguez, "Quantifying Raman Gain Coefficients in Tellurite Glasses," J. of Non-Cryst. Solids 345-356, 396-401 (2004).

20. J. Dexpert-Ghys, B. Pirio, S. Rossignol, J. M. Réau, B. Tanguy, J. J. Videau, J. Portier, "Investigations by Raman scattering of the $\left[\mathrm{TeO}_{2}-\mathrm{RMO}_{0.5}\right](\mathrm{M}=\mathrm{Ag}$ or $\mathrm{Tl})$ glasses and of the related ionic conductors $\left[\mathrm{TeO}_{2-}\right.$ $\left.\mathrm{RMO}_{0.5}\right]_{(1-\mathrm{x})}[\mathrm{AgI}]_{\mathrm{x}}$, , J. Non-Cryst. Solids 170, 167-174 (1994).

21. B. Jeansannetas, P. Thomas, J. C. Champarnaud-Mesjard, B. Frit, "Crystal structure of $\mathrm{Tl}_{2} \mathrm{Te}_{3} \mathrm{O}_{7}$," Mat. Res. Bull. 32 (1), 51-58 (1997).

22. B. Jeansannetas, P. Marchet, P. Thomas, J. C. Champarnaud-Mesjard, B. Frit, "New investigations within the $\mathrm{TeO}_{2}$-rich part of the $\mathrm{Tl}_{2} \mathrm{O}-\mathrm{TeO}_{2}$ system," J. of Mat. Chem. 8 (4), 1039-1042 (1998).

23. B. Jeansannetas, "Synthèse et caractérisation de quelques phases cristallisées et vitreuses du ternaire thallium-tellure-oxygène: vers de nouveaux matériaux por l'optique nonlinéaire," Thesis (University of Limoge 1998).

24. M. Dutreilh-Colas, "Nouveaux matériaux pour l'optique nonlinéaire: synthèse et étude structurale de quelques phases cristallisées et vitreuses appartenant aux systèmes $\mathrm{TeO}_{2}-\mathrm{Tl}_{2} \mathrm{O}-\mathrm{Ga}_{2} \mathrm{O}_{3}$ et $\mathrm{TeO}_{2}-\mathrm{Tl}_{2} \mathrm{O}-\mathrm{PbO}$," Thesis (University of Limoges 2001).

25. R. Stegeman, C. Rivero, L. Jankovic, H. Kim, K. Richardson, G. Stegeman, P. Delfyett, Jr., "Raman gain measurements in bulk glass samples," manuscript in preparation.

26. R. H. Stolen, J. P Gordon, W. J. Tomlinson, H. A. Haus, "Raman response function of silica-core fibers," J. Opt. Soc. Am. B 6, 1159-1166 (1989).

27. I. Kang, T. Krauss, F. Wise, "Sensitive measurement of nonlinear refraction and two-photon absorption by spectrally resolved two-beam coupling," Opt. Lett. 22, 1077-1079 (1997).

28. R. H. Stolen and E. P. Ippen, "Raman gain in glass optical waveguides," Appl. Phys.Lett. 22, 273-276 (1972).

29. R. Hellwarth, J. Cherlow, T.-T. Yang, "Origin and frequency dependence of nonlinear optical susceptibilities of glasses," Phys. Rev. B 11, $964-967$ (1975).

30. M. Dutreilh-Colas, P. Thomas, J. C. Champarnaud-Mesjard, E. Fargin " $\mathrm{New} \mathrm{TeO}_{2}$ based glasses for nonlinear optical applications: study of the $\mathrm{Tl}_{2} \mathrm{O}-\mathrm{TeO}_{2}-\mathrm{Bi}_{2} \mathrm{O}_{3}, \mathrm{Tl}_{2} \mathrm{O}-\mathrm{TeO}_{2}-\mathrm{PbO}$ and $\mathrm{Tl}_{2} \mathrm{O}-\mathrm{TeO}_{2}-\mathrm{Ga}_{2} \mathrm{O}_{3}$ systems," Phys. Chem. Glasses 44, 349-352 (2003).

31. A. Berthereau, E. Fargin, A. Villezusanne, R. Olazcuaga, G. Le Flem, L.Ducasse, "Determination of local geometries around tellurium in $\mathrm{TeO}_{2}-\mathrm{Nb}_{2} \mathrm{O}_{5}$ and $\mathrm{TeO}_{2}-\mathrm{Al}_{2} \mathrm{O}_{3}$ oxide glasses by XANES and EXAFS: investigation of electronic properties of evidenced oxygen clusters by ab initio calculations," J. Sol. St. Chem. 126, 143-151 (1996).

$\# 6013$ - \$15.00 US

(C) 2005 OSA
Received 10 December 2004; revised 7 February 2005; accepted 9 February 2005 21 February 2005 / Vol. 13, No. 4 / OPTICS EXPRESS 1145 


\section{Introduction}

Raman amplification is an important technology that has made an impact on currently deployed commercial optical transmission systems. Current transmission systems use distributed Raman amplification in order to improve the noise figure [1]. Discrete Raman amplification is used in the form of germanium-doped silica fibers that also serve as dispersion compensation devices [2]. However, all of these devices utilize silica-based fibers, and it is well known that silicates are one of the weakest nonlinear glasses for Raman gain [3]. Theoretical predictions and Raman scattering experiments have been made on both oxide and non-oxide glasses to find materials that exhibit higher nonlinearities than silicates [4-6]. Chalcogenide glass is known to have the highest non-resonant nonlinearities of all glasses, but it also has high attenuation coefficients (on the order of meter ${ }^{-1}$ ) and low optical damage thresholds [7-10]. Tellurite glass has been thoroughly researched in terms of the role of its structure on optical nonlinearities and these glasses have exhibited some of the highest nonlinearities in oxide glasses known to date [11-22]. It has been shown that introducing thallium into a tellurite glass matrix can further increase the nonlinearity [12,20,21]. Here we report on the impact on the Raman gain by varying the tellurium to thallium ratio in a binary glass, and also the impact of adding $\mathrm{PbO}$ to the matrix for both Raman gain and surface optical damage threshold enhancement.

\section{Glass elaboration}

Glassy pellets were prepared by first melting the appropriate quantities of reagent grade chemicals - $\mathrm{PbO}$ (Aldrich, 99.5\%), $\mathrm{TeO}_{2}$ (prepared by decomposition at $550^{\circ} \mathrm{C}$ of commercial $\mathrm{H}_{6} \mathrm{TeO}_{6}$ (Aldrich, 99.9\%) and $\mathrm{Tl}_{2} \mathrm{TeO}_{3}$ (synthesised by heating at $350^{\circ} \mathrm{C}$ for 18 hours an intimate mixture of $\mathrm{TeO}_{2}$ and $\mathrm{Tl}_{2} \mathrm{CO}_{3}$ under a nitrogen atmosphere) in platinum crucibles for half an hour at $800^{\circ} \mathrm{C}$. The melts were then quickly quenched by flattening between two brass blocks separated by a brass ring to obtain cylindrical samples $10 \mathrm{~mm}$ wide and 1-3 mm thick and a cooling rate of about $10^{4} \mathrm{~K} / \mathrm{s}$ was utilized.

Seven samples from two different families $\left(\mathrm{TeO}_{2}-\mathrm{TlO}_{0.5}\right.$ and $\left.\mathrm{TeO}_{2}-\mathrm{TlO}_{0.5}-\mathrm{PbO}\right)$ were prepared using this technique. Figure 1 displays the dispersion in the absorption coefficient measured with a Cary 500 spectrophotometer for the tellurite glasses in this paper and in [18]. The samples were optically polished to allow optical beams of $125 \mu \mathrm{m}$ beam waist to pass through 1-3 mm of the glass with minimum scattering. The glasses reported in $[12,30]$ and reported here were fabricated by the same research group. The density, glass transition and crystallization temperatures, and thermal stability of the different glass samples have been reported elsewhere [22-24].

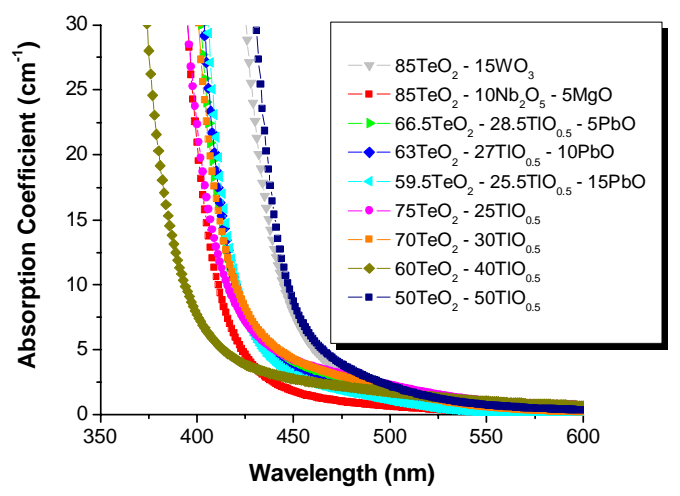

Fig. 1. Dispersion in the absorption coefficient for the tellurite glasses tested for Raman gain.

\#6013 - \$15.00 US

(C) 2005 OSA
Received 10 December 2004; revised 7 February 2005; accepted 9 February 2005 21 February 2005 / Vol. 13, No. 4 / OPTICS EXPRESS 1146 


\section{Experimental procedure}

The procedure to test for Raman gain in bulk glass samples has been reported previously and further clarification is currently being provided $[18,25]$. In summary, picosecond pulses of high irradiance at $1064 \mathrm{~nm}$ are used as a pump source and a wavelength tunable source from an OPG/OPA is used as the amplified probe. A femtosecond source was avoided because the response time of the Raman vibrations is reported to be on the order of hundreds of femtoseconds [26,27]. Since Raman gain is primarily a polarization-sensitive process, the probe is linearly polarized $45^{0}$ with respect to the linear pump polarization. The polarization of the probe beam parallel to the pump beam polarization is used to detect approximately $10 \%$ gain, while the polarization of the probe beam orthogonal to the pump beam polarization is the "effective" input energy. The depolarization ratio (VV/VH) - obtained from spontaneous Raman scattering experiments on the same glasses - is used as a correction factor since the probe beam polarization orthogonal to the pump beam polarization does experience minor Raman excitations in these glasses [11]. After propagation through the sample a monochromator is used to filter the pump from the probe wavelength, and the two probe polarizations enter two identical, calibrated germanium detectors via a polarizing beam splitter. In concert with a calibrated silicon detector for the $1064 \mathrm{~nm}$ pump, Raman gain can be measured on a shot-to-shot basis, and averaging is done over hundreds of shots. An indepth overview of this approach and procedure will be provided in [25]. The experimental apparatus is calibrated on a $3.18 \mathrm{~mm}$ thick Corning $7980-2 \mathrm{~F}$ fused silica sample (peak Raman gain $=1.1 \times 10^{-13} \mathrm{~m} / \mathrm{W}$ in good agreement with published values), and corrections are made for Fresnel reflections at the surfaces with the corresponding index of refraction data and depolarization ratio $[28,29]$. The Raman gain data published in [18] have been compared to cross-section calculations based on spontaneous Raman scattering experiments and have shown to be in good agreement for the $\Delta v=20 \mathrm{THz}$ frequency shift studied [19].

\section{Results and interpretation}

The measured Raman gain values have been overlaid with the spontaneous Raman scattering spectra for the three $\mathrm{TeO}_{2}-\mathrm{TlO}_{0.5}-\mathrm{PbO}$ glasses investigated. The spontaneous Raman spectra were obtained using a $90^{\circ}$ scattering configuration with an excitation wavelength of $780 \mathrm{~nm}$ to obtain scattering data at a wavelength much longer than the band edges. The decrease in the spontaneous Raman data at low frequency shifts in Fig. 2 is caused by the cut-off of the notch filter used to discriminate the spontaneous Raman scattering from Rayleigh scattering. The Bose-Einstein correction factor has been applied to the spontaneous Raman scattering data. Figure 2(a) displays a peak experimentally obtained Raman gain coefficient of ( $42 \pm 1.5)$ times that of the Corning 7290 fused silica sample for the composition $59.5 \mathrm{TeO}_{2}-25.5 \mathrm{TlO}_{0.5}$ - $15 \mathrm{PbO}$. Figure 2(b) demonstrates the Raman gain curve for $63 \mathrm{TeO}_{2}-27 \mathrm{TlO}_{0.5}-10 \mathrm{PbO}$, and Fig. 2(c) shows the Raman gain curve for $66.5 \mathrm{TeO}_{2}-28.5 \mathrm{TlO}_{0.5}-5 \mathrm{PbO}$. Table 1 illustrates how the peak at $\Delta v=20 \mathrm{THz}$ caused by the vibrations of the $\mathrm{TeO}_{4}$ units and the peak at $\Delta v=21.3 \mathrm{THz}$ caused by the vibrations of the $\mathrm{TeO}_{3}$ and $\mathrm{TeO}_{3+1}$ units vary with molar concentration within the glass matrix, and lists the measured optical surface damage thresholds. It is not yet known why the addition of $\mathrm{PbO}$ to the glass matrix increases the surface optical damage threshold over the binary $\mathrm{TeO}_{2}-\mathrm{TlO}_{0.5}$ glasses based on previous analysis of identical compositions [30]. However, we believe it is related to the role of $\mathrm{PbO}$ as a network participant in the ternary glasses. While lead is known to act as a modifier in very small molar quantities, it can serve as an intermediate or partner former in some glass compositions. The addition to the glass in the previous role would allow the average bond strength of the glass to be enhanced, thus "hardening" the material's laser damage resistance. A systematic study to evaluate this trend in these and other glass systems is necessary to validate these structure-based assumptions. 

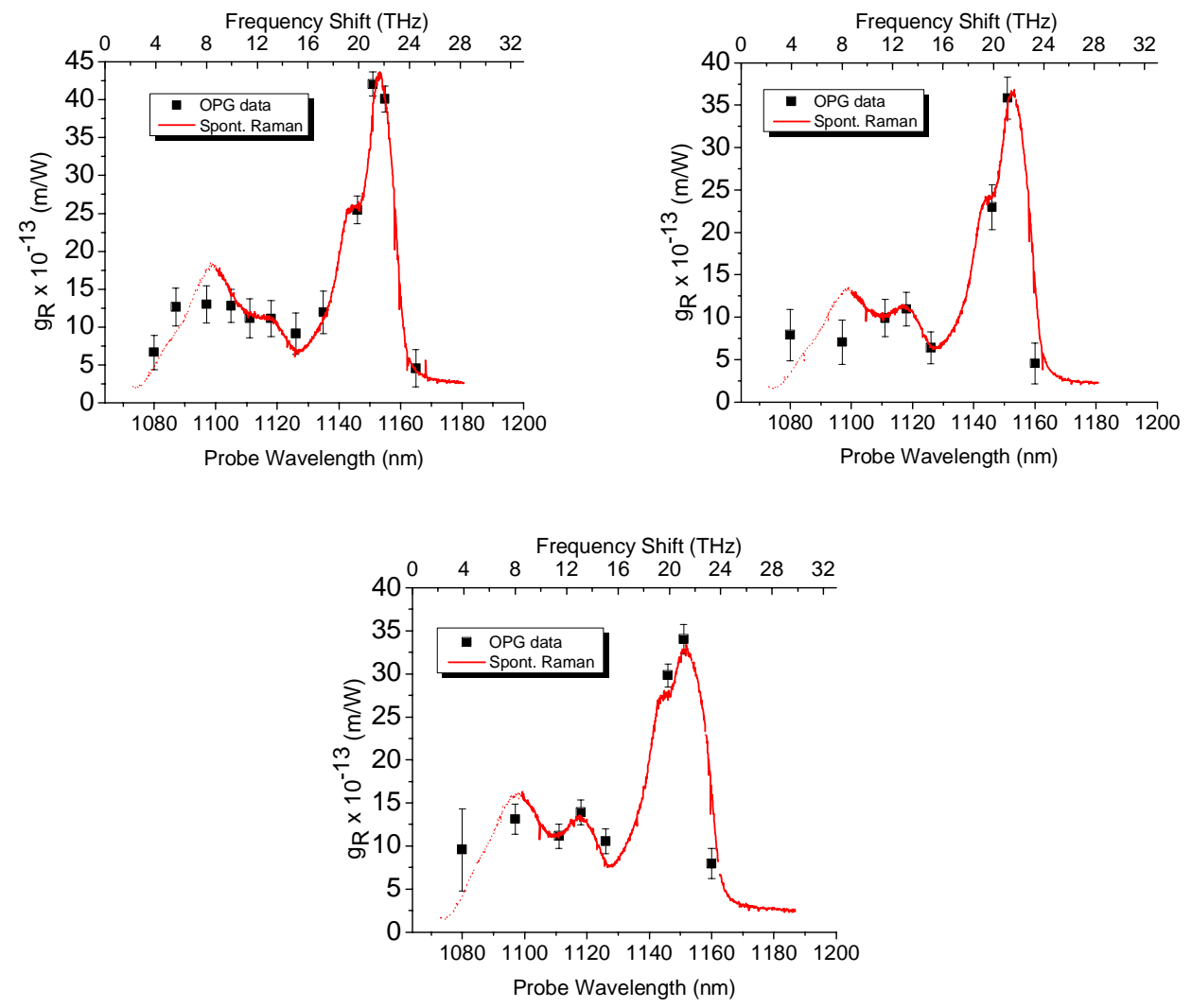

Figs. 2. (a), (b), and (c). Raman gain curve of (a) $59.5 \mathrm{TeO}_{2}-25.5 \mathrm{TlO}_{0.5}-15 \mathrm{PbO}$, (b) $63 \mathrm{TeO}_{2}$ $-27 \mathrm{TlO}_{0.5}-10 \mathrm{PbO}$, and (c) $66.5 \mathrm{TeO}_{2}-28.5 \mathrm{TlO}_{0.5}-5 \mathrm{PbO}$

Table 1. Raman gain coefficients of $\mathrm{TeO}_{4}(\Delta v=20 \mathrm{THz})$ units and $\mathrm{TeO}_{3}$ and/or $\mathrm{TeO}_{3+1}$ units $(\Delta v=21.3 \mathrm{THz})$ resonances and optical surface damage thresholds

\begin{tabular}{cccc}
\hline $\begin{array}{c}\text { Glass Composition } \\
\text { (Molar Percent) }\end{array}$ & $\begin{array}{c}\Delta v=20 \mathrm{THz} \\
\mathrm{Gain} \text { coef. } \\
\left(10^{-13} \mathrm{~m} / \mathrm{W}\right)\end{array}$ & $\begin{array}{c}\Delta v=21.3 \mathrm{THz} \\
\text { Gain coef. } \\
\left(10^{-13} \mathrm{~m} / \mathrm{W}\right)\end{array}$ & $\begin{array}{c}\text { Optical surface damage } \\
\text { threshold }\left(\mathrm{GW} / \mathrm{cm}^{2}\right)\end{array}$ \\
\hline $66.5 \mathrm{TeO}_{2}-28.5 \mathrm{TlO}_{0.5}-5 \mathrm{PbO}$ & $30 \pm 1.5$ & $34 \pm 1.7$ & 8.5 \\
$63 \mathrm{TeO}_{2}-27 \mathrm{TlO}_{0.5}-10 \mathrm{PbO}$ & $23 \pm 2.6$ & $38 \pm 2.5$ & 8.5 \\
$59.5 \mathrm{TeO}_{2}-25.5 \mathrm{TiO}_{0.5}-15 \mathrm{PbO}$ & $25 \pm 2$ & $42 \pm 1.5$ & 8.3 \\
$75 \mathrm{TeO}_{2}-25 \mathrm{TlO}_{0.5}$ & $25 \pm 4$ & $19 \pm 3$ & 3.6 \\
$70 \mathrm{TeO}_{2}-30 \mathrm{TlO}_{0.5}$ & $21 \pm 4$ & $23 \pm 5$ & 4.4 \\
$60 \mathrm{TeO}_{2}-40 \mathrm{TlO}_{0.5}$ & $21 \pm 5$ & $30 \pm 7$ & 4.0 \\
$50 \mathrm{TeO}_{2}-50 \mathrm{TlO}_{0.5}$ & $19 \pm 3$ & $58 \pm 3$ & 5.1 \\
\hline
\end{tabular}

The damage threshold of the binary $\mathrm{TeO}_{2}-\mathrm{TlO}_{0.5}$ glasses was low enough to produce unreliable data off of the main $\Delta v=20 \mathrm{THz}$ and $\Delta v=21.3 \mathrm{THz}$ peaks in the Raman gain spectrum. Most attempts to measure Raman gain away from these main peaks resulted in surface optical damage after less than five minutes of exposure to the $10 \mathrm{~Hz}$ system. Nevertheless, Raman gain measurements were made over the $\Delta v=20 \mathrm{THz}$ and $\Delta v=21.3$ $\mathrm{THz}$ bands for all four binary compositions and agree with structural variation analysis of these glasses [11,12,19-21].

In essence, a tellurium rich glass contains many $\mathrm{TeO}_{4}$ disphenoids with the lone pair electrons so directed as to constitute the third equatorial corner of a $\mathrm{TeO}_{4} \mathrm{E}$ trigonal 
bipyramid; these are the most polarizable entities in the glass network and are responsible for the $\Delta v=20 \mathrm{THz}$ vibration as shown by ab initio calculations [31]. By combining another structural unit to the glass matrix that also has a Lewis $\mathrm{ns}^{2}$ lone pair, it can be anticipated that the nonlinearity of the glass can increase due to strengthened stereochemical activity [11,12]. Addition of a third species which contains a Lewis $\mathrm{ns}^{2}$ lone pair, in this case $\mathrm{PbO}$, has also shown to further increase the purely electronic third order nonlinearity $\mathrm{n}_{2}$ in these glasses [29]. As the mole $\%$ of tellurium decreases, the $\mathrm{TeO}_{4}$ units distort to form $\mathrm{TeO}_{3+1}$ units and then to $\mathrm{TeO}_{3}$ units, which have vibrational resonances at a frequency shift near $21.3 \mathrm{THz}$. This last large resonance, which is stronger than the $\mathrm{TeO}_{4}$ vibrational resonance in these glasses, should be related to the presence of thallium ions in the vicinity of the $\mathrm{TeO}_{3}$ and $\mathrm{TeO}_{3+1}$ units. In this frequency range, no Raman band could be related to the presence of thallium oxide groups. NMR investigations are ongoing to evaluate the thallium ions environment in these glasses.

As the ratio of tellurium oxide to thallium oxide is varied, the $\Delta v=20 \mathrm{THz}$ and $\Delta v=$ $21.3 \mathrm{THz}$ bands vary in terms of strength in the Raman gain curve. A peak Raman gain coefficient of $(58 \pm 3)$ times that of the peak Raman gain of the fused silica sample is reported for the binary sample containing $50 \%$ mole of $\mathrm{TlO}_{0.5}$. This represents the highest directly measured and reported peak Raman gain coefficient to date in oxide glasses known to the authors. With the band edges below $500 \mathrm{~nm}$ for all of the samples tested, it is reasonable to expect similar performance at the telecommunication wavelengths of $1280-1625 \mathrm{~nm}$ because the Raman gain measurements were made with $1064 \mathrm{~nm}$ pumping which avoids any resonantly enhanced Raman effects. Furthermore, the increased peak Raman gain coefficient with increasing thallium oxide content reported here shows a trend of increasing non-resonant nonlinearity with increasing thallium content in the glass matrix, in partial agreement with the trend listed in Table 1 in [30] for purely real electronic $\chi^{(3)}$ measurements. The reasons for some of the discrepancies reported in this work and in [30] are currently being investigated.

\section{Conclusion}

Several tellurium-thallium oxide glass compositions were fabricated and tested for their performance as a candidate for development into Raman amplifiers. Compositions rich in thallium oxide content exhibited the highest directly measured peak Raman gain coefficients for oxide glasses to date. Addition of $\mathrm{PbO}$ to the glass matrix significantly increased the optical surface damage threshold of the glass, a necessary criteria for materials to be used in high power Raman applications. The trends in the Raman gain data are in partial agreement with $\mathrm{n}_{2}$ measurements made on separate $\mathrm{TeO}_{2}-\mathrm{TlO}_{0.5}$ glasses as compared to fused silica.

\section{Acknowledgments}

This work was carried out with the support of numerous research, equipment, and educational grants, including NSF grants ECS-0123484, ECS-0225930, and NSF Integrative Graduate Education and Research Training (IGERT) grant DGE-0114418. The US authors also acknowledge the assistance and financial support of the College of Optics and Photonics and the Student Government Association (SGA) at the University of Central Florida, as well as an equipment donation from JDS Uniphase. The work in France was supported by NSF-CNRS \# 13050. Special thanks to David Morgan for the fruitful discussions and assistance in the laboratory. 